\title{
LA CONSTITUCIONALIZACIÓN DE LA RAZONABILIDAD COMO IMPERATIVO
}

\author{
The constitutionalization of reasonableness how imperative
}

Teresita RENDÓN HUERTA BARRERA ${ }^{1}$

\begin{abstract}
Sumario
Introducción I. La razonabilidad. II. El derecho a la razonabilidad. III. El derecho a la razonabilidad dentro del Estado constitucional de derecho. IV. El Estado constitucional de derecho. V. La constitucionalización de la razonabilidad como imperativo. VI. Conclusiones. VII. Fuentes.
\end{abstract}

Resumen: El presente artículo se refiere a la razonabilidad no solo como un principio que debe regir la actuación de los juzgadores u orientar la emisión de las leyes, sino como un derecho fundamental.

Palabras clave: principio de razonabilidad, derecho a la razonabilidad, Estado constitucional y razonabilidad.

Abstract: This article refers to the reasonableness not only as a principle that should govern the actions of judges or direct the issuance of laws, but as a fundamental right.

Keywords: principle of reasonableness, right to reasonableness, constitutional state and reasonableness.

\section{INTRODUCCIÓN}

En el ámbito de las relaciones entre derecho y poder impera un derecho constitucionalizado y un poder de Estado decididamente sometido a la Constitución. De ahí que vale explicitar un derecho que va más allá del debido proceso sustantivo, que lo es el derecho a la razonabilidad. La dirección que ha de tomar es más compleja y amplia que la de una mera reforma constitucional. La hipótesis que sustenta este trabajo es que la razonabilidad no solo es un principio que debe regir la actuación de los juzgadores u orientar la emisión de las leyes, en tanto en cuanto se trata de un derecho fundamental oponible frente a toda autoridad.

\footnotetext{
${ }^{1}$ Doctora en Derecho por la Universidad Nacional Autónoma de México, con especialidad en Derecho Constitucional y Administrativo. Profesora Investigadora y actualmente Directora de la División de Derecho Política y Gobierno, campus Guanajuato de la Universidad de Guanajuato, México. Autora de las obras Derecho Municipal, Porrúa, México, 2007; Ética del Juzgador, Suprema Corte de Justicia de la Nación, México; Los Conceptos Jurídicos Indeterminados en el Derecho Administrativo, Quito, Ecuador, 2012; Teoría y Técnica de la Reglamentación Municipal en México, Porrúa, 2013. Con nombramiento de Investigador Nacional por el Consejo Nacional de Ciencia y Tecnología de México. Miembro del cuerpo académico: Ciencia Penal, Estado de Derecho y Derecho Humano.
} 
Se trata en realidad sí, de una propuesta relativa a la limitación del ejercicio del poder, pero además, de desafiar la dogmática de los derechos fundamentales, lo cual no solo implica el reconocimiento expreso de un derecho, sino que además, debe abarcar la actuación del Estado mediante estrategias jurídicas proactivas. Consecuentemente, no basta con asegurar su dimensión subjetiva. En todo caso, tendrá que afirmarse su aspecto objetivo, tanto constitucionalmente, como en el momento de la interpretación, que ha de ser siempre acorde a la Constitución. El derecho a la razonabilidad debe, por tanto, protegerse mediante reglas, procedimientos y organización adecuados. En el ámbito de los derechos fundamentales, el derecho a la razonabilidad debe tener un lugar específico.

Siendo parte de la estructura esencial del ordenamiento, el derecho a la razonabilidad implica el derecho a la argumentación como parte de la seguridad jurídica, por ser inherente a la dignidad racional de la persona humana, con un carácter universal, inalienable, imprescriptible, intransferible e inviolable.

Bajo estas premisas, el derecho a la razonabilidad no es solo un límite para la administración, sino un imperativo para el poder público en general. Constitucionalmente, el derecho a la razonabilidad debe estar inscrito dentro de los derechos fundamentales. Entendiéndose como la garantía de que toda autoridad emita decisiones jurídicas razonables, no solo fundadas, motivadas y de acuerdo al debido proceso.

Debe, asimismo, estar explícitamente reconocido tomando en cuenta que desde el momento que los derechos fundamentales están reafirmados por principios y normas constitucionales, no son meros enunciados. Constituyen derecho positivo pleno protegido por las normas de garantía de la Constitución.

\section{LA RAZONABILIDAD}

Como principio, la razonabilidad es una herramienta del control de la constitucionalidad de las leyes que hunde sus raíces en la Carta Magna, impuesta por los nobles ingleses al rey Juan Sin Tierra en 1215, pero su actual perfil es el resultado de una larga jurisprudencia de diversísimos tribunales con jurisdicción constitucional: se aplica en Estados Unidos, Alemania, España, Italia y, en la práctica, en la totalidad de los países occidentales.

El principio prescribe, básicamente, que los jueces deben declarar la inconstitucionalidad de aquellas leyes que regulen de un modo irrazonable los derechos constitucionales. Se trata de un "concepto jurídico indeterminado", es decir, de un concepto amplio cuyo significado preciso se determina caso por caso, en el momento de su utilización.

[...] la irrazonabilidad equivale a "alteración" de los derechos afectados por la ley que se examina. Es decir, una ley será irrazonable, y por tanto inconstitucional, si "altera” los derechos humanos que se encuentran involucrados en ella. ${ }^{2}$

El tratamiento del aspecto objetivo de la razonabilidad, surge del contraste de la norma y el hecho, en tanto está sujeto al principio de consistencia, que reside en una construcción mental llevada a cabo mediante procedimientos lógicos.

\footnotetext{
2 CIANCIARDO, Juan, “El punto final para el principio de razonabilidad.” Periódico La Nación, en: http:// www.lanacion.com.ar/371576-el-punto-final-para-el-principio-de-razonabilidad, 9 de enero de 2013. 
Mientras que el aspecto subjetivo de la razonabilidad, es cuando ésta resulta como conclusión de un proceso de interpretación, fruto de ponderaciones y meritaciones que realiza el juez, inspirado en los valores y principios que informen su conciencia jurídica y atendiendo a las circunstancias que connotan los hechos. [....] En consecuencia y concluyendo ya mis reflexiones, señalaré con Linares que la razonabilidad es un estándar aixiológico, un módulo de justicia que nos ayuda a determinar lo axiológicamente válido del orden jurídico, según las circunstancias del caso y en función de todos los valores.

Llevada esta fórmula al plano constitucional, ella adquiere un rol propio a través del "control de razonabilidad", y se nos presenta con todo el vigor de una garantía constitucional implícita y específica, manifestativa de la superlativa garantía del "control de constitucionalidad" y de la "supremacía constitucional" en que se funda. En fin, desentrañar la razonabilidad de una norma reglamentaria o de las circunstancias de su aplicación, es asegurar su constitucionalidad, para que la Ley Suprema vivifique la conciencia jurídica de la sociedad en el afianzamiento de la justicia preambular ${ }^{3}$

Bidart Campos sostiene que el enunciado del principio de legalidad debería ser: "nadie puede ser obligado a hacer lo que la ley "justa" — o razonable — no manda, ni privado de lo que prohíbe". ${ }^{4}$

La razonabilidad, entonces, pasa a constituirse

[...] en la base del 'debido proceso sustantivo' y, así, cuando se violenta aquélla no nos encontramos frente a una transgresión al debido proceso en sentido formal o adjetivo, como imposición de una forma o de un procedimiento que deben seguir los actos constitucionales de cada órgano del Estado para ser válidos, sino que lo que se agrede es una cuestión esencial o de fondo: el ajuste de todo acto con el sentido de justicia que la Constitución alberga. ${ }^{5}$

Partiendo de esta premisa básica - la razonabilidad es una exigencia constitucional que da contenido de justicia a la legalidad como principio formal- la cuestión está, no obstante, lejos de agotarse. En este aspecto el primer interrogante que surge y cuya respuesta intentaremos ir otorgando a lo largo de este ensayo, será justamente qué debe entenderse por 'razonable.'

La tesis central del liberalismo político de John Rawls es que una teoría de la justicia está justificada si es aceptable para toda persona razonable. Rawls establece una diferencia entre racionalidad práctica y razonabilidad que se remonta a Kant:

\footnotetext{
3 HARO, Ricardo, "La Razonabilidad y las Funciones de Control," Ius et Praxis, versión On-line ISSN 0718-0012, Año 7 No 2: 179 - 186, 2001. Consultado en: http://www.scielo.cl/scielo.php?pid=So718o0122001000200oo8\&script=sci_arttext, el 5 de febrero de 2013.

4 BIDART CAMPOS, Germán, Manual de la Constitución Reformada, Buenos Aires, Ediar,1999, Tomo I, p. 514.

5 DEANE, Matías Mariano, El Principio de Razonabilidad, Buenos Aires, Colegio de Magistrados y Funcionarios de la Provincia de Buenos Aires, s.a., p. 14.

${ }^{6}$ Ibídem.
} 
[...] Lo racional es, sin embargo, una idea diferente de lo razonable y se aplica a [...] un agente que tiene capacidad de juicio y deliberación en la búsqueda de los fines e intereses que le son peculiarmente propios. Lo racional se aplica a cómo se adoptan y afirman estos fines e intereses, al igual que a cómo se les da prioridad. Se aplica también a la elección de los medios. ${ }^{7}$

La razonabilidad como una exigencia implícita en la idea de justicia, y como la mejor forma de determinar objetivamente

[...] el contenido esencial de un derecho fundamental, es asumiendo un parámetro para evaluar la razonabilidad de la norma restrictiva. En los sistemas de herencia romano germánica cobró relevancia luego de la Segunda Guerra Mundial, con la caída de las concepciones positivistas del derecho y el resurgimiento de ideas iusnaturalistas. Con esto, se abrió la posibilidad al examen de la legitimidad del proceder legislativo en materia regulatoria de derechos fundamentales, por parte de los Tribunales Constitucionales, como una forma de excluir de las disposiciones todo rastro de arbitrariedad. ${ }^{8}$

La razonabilidad se ha centrado en la acción, considerada desde la perspectiva personal - aspecto subjetivo- o desde una perspectiva universal - aspecto objetivo-. La primera es de aproximación apenas problemática porque permite analizar la cuestión por la vía introspectiva, inmediatamente patente.

a) La acción subjetivamente razonable no es la instintiva, promovida por pautas innatas, como el hambre primaria. Los irracionales son sujetos de tales conductas y solo de ellas. El hombre, por su condición de animal racional, es ambivalente: puede obrar lógica o ilógicamente. Tampoco es la acción meramente refleja aunque responda a un hábito esforzadamente adquirido; tal comportamiento tiene una estructura análoga a la instintiva puesto que responde a un cierto mecanicismo. [....] Una acción subjetivamente razonable ha de ser querida, es decir, explícitamente voluntaria aunque esté más o menos condicionada y limitada por las circunstancias internas y externas. b) La acción subjetivamente razonable no es la aleatoria, [....] Es una acción que se orienta hacia una meta previamente elegida, aunque luego resulte que no se alcanza plenamente. La determinación consciente de un deseado término 'ad quem' es una condición necesaria. Los irracionales actúan solo por estímulos, no por motivos. La acción subjetivamente razonable es finalista. Este dato psicológico se suele extrapolar hasta afirmar una finalidad intrínseca de todo ente y, por lo tanto, del cosmos; pero no se trata ahora de tal axioma metafísico, sino de la conciencia

\footnotetext{
7 RAWLS, John, Liberalismo político, traducido por Sergio René Madero Báez, México, FCE, UNAM, 1995, p. 50.

8 VARGAS ALFARO, Marvin de Jesús, El control de Razonabilidad de las Leyes en la Jurisprudencia de la Sala Constitucional de la Corte Suprema de Justicia, Tesis para optar por el Grado de Licenciado en Derecho, Costa Rica, Universidad de Costa Rica, San José, 2009.
} 
de actuar con un propósito concreto. Es una vivencia humana tan frecuente que un modo fundamental de comprender el comportamiento ajeno es averiguar a qué aspira. ${ }^{9}$

Popper considera que aceptan la razonabilidad aquellos que no olvidan sus errores o sea, la falibilidad, ya que supone necesariamente la humildad intelectual. De ahí que el racionalismo crítico resida en la razonabilidad como implicación del falibilismo:

[...] Creo que tengo razón, pero yo puedo estar equivocado y ser usted quien tenga la razón; en todo caso, discutámoslo, pues de esta manera es más probable que nos acerquemos a una verdadera comprensión que si meramente insistimos ambos en que tenemos razón. $^{10}$

Próximo a la ética kantiana — no a su epistemología - el racionalismo crítico es la crítica racional que se deriva del falibilismo popperiano. ${ }^{11}$

Así, la razonabilidad es una de esas nociones que van ganando terreno en el mundo jurídico, como:

[...] fruto de una conciencia cada vez más clara, de que la compleja realidad no se deja limitar fácilmente por el concepto acabado. Los conceptos jurídicos indeterminados, entre los que se cita la 'razonabilidad', son instrumentos legales que apelan a la prudencia judicial, poseedora de un amplio margen de discrecionalidad interpretativa, para que determine la correcta solución a la luz de las circunstancias del caso. ${ }^{12}$

Todos los anteriores elementos sirvieron de base para preparar este trabajo. La labor no estuvo exenta de dificultades, siendo la mayor de todas, la de tratar de desarrollar solventemente una base conceptual a partir de una perspectiva teórica, sin por eso declinar el discernimiento y trascendencia que en la práctica tiene el tema.

\section{EL DERECHO A LA RAZONABILIDAD}

El derecho a la razonabilidad trasciende directamente en la seguridad jurídica de los ciudadanos, porque merced a ella, no puede haber distancia entre principios constitucionales, valores, legislación y decisión de autoridad. El derecho a la razonabilidad pertenece al núcleo irreductible de los derechos fundamentales como derechos de defensa frente a las injerencias de los poderes públicos. El derecho a la razonabilidad entendido como un derecho fundamental, nada tiene que ver con el mero legalismo, procesalismo o formalismo. Antes bien, consiste en la protección de las razones que dotan de contenido y dan sentido a la decisión de toda autoridad y con ello, a los demás derechos fundamentales.

El interés por la razonabilidad, sobre todo, como principio, no es nuevo. Pero la especial atención a la razonabilidad como derecho fundamental, es un enfoque especial, una toma de conciencia de un derecho fundamental erga omnes, independientemente de su concep-

9 FERNÁNDEZ DE LA MORA, Gonzalo, “El Imperativo de Razonabilidad”, revista Razón Española, Madrid, Marzo-Abril 200o, Separata facticia, pp. 14.

${ }^{10}$ POPPER, Karl, Conjeturas y refutaciones, Paidós, Barcelona, 1994, p. 426.

${ }^{11}$ Se trata de una posición metodológica y ética.

12 BAZÁN L., José Luis, “Racionalidad y Razonabilidad en el Derecho”, Revista Chilena de Derecho, Chile, Pontificia Universidad Católica de Chile, Vol. 18, No 2, pp. 179-191. 
ción metapositiva. En el plano jurídico-positivo, los derechos fundamentales no pueden ser otra cosa que atributos legales en sentido estricto, tal como lo afirma Jiménez Campo: "el derecho fundamental vive a través y por medio de una legalidad a falta de la cual resulta impracticable." ${ }^{13}$ No se trata, por tanto, de afirmar su existencia como derecho natural, sino de garantizar su dimensión objetiva, de buscar su positivación como componente estructural básico del orden jurídico por decisión del Constituyente.

La razonabilidad, en consecuencia, debe ser una expresión jurídico-positiva de un orden de valores que existe extra y preconstitucionalmente. Se trata de un verdadero derecho jurídico, con protección jurídica exigible ante los jueces, en la actuación de éstos mismos, de los legisladores y de las autoridades administrativas.

Entre los efectos de la objetivación del derecho a la razonabilidad, está la denominada irradiación sobre el ordenamiento jurídico, que implica también su eficacia entre particulares.

En la concepción clásica del Estado de derecho, la argumentación es inherente a la defensa de la seguridad jurídica frente a la indeterminación. En tanto el aspecto objetivo se concreta en la correspondencia práctica entre la Constitución y la emisión de la decisión.

\section{EL DERECHO A LA RAZONABILIDAD DENTRO DEL ESTADO CONSTITUCIONAL DE DERECHO}

Rudolf von Ihering, profundo conocedor de las instituciones jurídicas de la antigüedad, menciona:

[.... Se ha observado que (son indestructibles) los pueblos (que tienen) una sobriedad de vida, y naturaleza incapaz de precipitación y de indecisión y que están destinados por encima de todo, al cultivo del derecho. [...] La defensa del derecho es un deber que tenemos para con la sociedad. Para hacerlo, debemos ante todo mostrar la relación que existe entre el derecho objetivo y el subjetivo. ${ }^{14}[\ldots]$ El interés de esa lucha no está limitado de ningún modo al derecho privado o a la vida privada, va mucho más allá de eso. Una nación es finalmente, la suma de todos los individuos particulares, y según los individuos particulares sienten, piensan, obran, así siente, piensa, obra la nación. ${ }^{15}$

Por su parte, Fritz Schulz, alude a la actitud conservadora que se mantuvo "con asombrosa constancia en la historia del Derecho romano y dominó a los hombres de la república, a los del principado y a los del bajo imperio; incluso en el círculo que rodeó a Justiniano como lo demuestra su Corpus Juris, o un plan como el de las Pandectas, que consideraba la jurisprudencia clásica como presente y no como pasado, formando una unidad con la jurisprudencia bizantina". ${ }^{16}$

Hoy día es necesario abrir un espacio para la reflexión sobre las consecuencias desastrosas que pueden esperarse si sigue dándose tan poca importancia al derecho. Frente a la

\footnotetext{
${ }^{13}$ JIMÉNEZ CAMPO, Javier, "El legislador de los derechos fundamentales”, Estudios de Derecho Público en Homenaje a Ignacio de Otto, España, Universidad de Oviedo, 1993, pp.70 y ss.

14 IHERING, Rudolf von, La lucha por el Derecho, Buenos Aires, Valletta Ediciones, 2004, p. 85, 2 da. Edición.

15 Supra Ib. p. 60 .

${ }^{16}$ SCHULZ, Fritz, Derecho romano clásico, Traducción de José Santa Cruz Teigeiro, Barcelona, Bosch, 1960, p. 11 y 18.
} 
aspiración universal de conservar la vida, de buscar la paz, la seguridad y la justicia social, múltiples peligros se ciernen sobre la humanidad, limitando o impidiendo su consecución.

Puede afirmarse sin vacilación, que lo que construye al Estado y también a la nación, es la historia, son los valores ${ }^{17}$ que el pueblo asume como propios en la Constitución y en el derecho, al que todos estamos subordinados y al decir todos, es claro que aludimos a los gobernados, a los gobernantes y específicamente, a quienes se ha confiado la interpretación y la aplicación de la ley, proceso que solo se justifica en función de la razonabilidad.

La razonabilidad es una actitud de la razón práctica que por medio de la argumentación, llega a la toma de decisiones.

En los momentos de decisión, se involucra un elemento de carácter deóntico obligatorio, de ahí que la razonabilidad sea inmanente a la aplicación de las normas y por tanto, principio sine qua non del Estado de derecho. Dice Popper: "La ética no es una ciencia. Pero aunque no existe ninguna base científica racional de la ética, existe en cambio una base ética de la ciencia y del racionalismo" ${ }^{18}$

Si el Estado de derecho surge como dique al Estado totalitario, donde el monarca se encontraba por encima de todos los ciudadanos y podía disponer y decidir sin límite alguno, es relevante para esta investigación, mencionar la evolución que ha tenido el concepto de Estado de derecho, en tanto el derecho a la razonabilidad, representa un avance dentro del Estado constitucional de derecho, como límite al poder del Estado.

Evolución del concepto de Estado de derecho

1. Primer antecedente: Rule of law es un concepto preconstitucional del siglo XVII surgido en Inglaterra que significó sometimiento a la ley.

2. Segundo antecedente: El modelo que nace de la Revolución Francesa a partir de la Declaración de los Derechos del Hombre.

3. Tercer antecedente: La voz: "Rechstaat" acuñada por el jurista y político alemán Robert Von Mohl (Stuttgart,1799-Berlín, 1875), para significar la regulación, sometimiento y control de la colectividad y del poder público, de sus órganos y funciones por medio del derecho.

El Estado de derecho es:

1. Una construcción dinámica e histórica.

2. Un orden en el que los derechos fundamentales están satisfechos.

3. La presencia de límites al poder público.

4. La colaboración de poderes.

5. La existencia una Constitución escrita y de una jerarquía normativa que deriva de ésta.

17 ÁLVAREZ GARDIOL, Ariel, Introducción a una teoría general del derecho: El método jurídico, Buenos Aires, Astrea, 1975, p. 137: “Los valores jurídicos funcionan como pautas de valoración fuera del sistema y sirven como atalayas desde cuyas cimas es posible evaluar los valores jurídicos que contiene un determinado jurídico".

18 POPPER, Karl, La sociedad abierta y sus enemigos, Barcelona, Paidós, 200o, p. 404. 
El combate a la corrupción. "[...] surge con la democracia, pues en ésta se dan las condiciones para que se conozcan los hechos porque la oposición puede controlar al gobierno, la prensa tiene la posibilidad de informar de ello y los órganos fiscalizadores actúan con mayor libertad". ${ }^{19}$

El Estado contemporáneo es concebido en los sistemas jurídicos de occidente, como un Estado sometido al derecho. La Constitución es por una parte, la forma en que se manifiesta la soberanía nacional y por otra, el fundamento jurídico de todas las actividades de los órganos estatales, así como de las actividades facultadas y protegidas de los particulares. ${ }^{20}$

Un Estado de derecho no se limita a la conformación de un sistema jurídico, implica una cultura, el ejercicio efectivo del poder en beneficio del pueblo y el adecuado servicio a la comunidad por medio de las instituciones.

La sociedad percibe un rompimiento grave del Estado de derecho, que se traduce en debilidad de las instituciones, falta de calidad de la administración, vulnerabilidad de los derechos básicos de la población, desconfianza en muchas instituciones, alta percepción de la corrupción, la impunidad, la arbitrariedad y la ilegalidad como algo "normal", desaliento en la utilización de los medios formales, incremento en el uso de medios no jurídicos para la solución de conflictos.

Las deficiencias del Estado de derecho han favorecido la corrupción en sus diversas modalidades, el autoritarismo, indebido manejo del poder discrecional, irregularidades en materia de concesiones, autorizaciones, permisos y contratos otorgados por favores, financiación de campañas electorales con fondos de procedencia ilícita, tráfico de influencias, nepotismo, promoción de la imagen personal de los funcionarios, gastos superfluos — siendo necesario establecer el control por el fin y no solo numérico-, alteración de documentos y es en esos bordes en donde se utiliza la acusación sobre corrupción como presión, manejando la negociación política como instrumento de impunidad, por mencionar solo algunos casos.

Habrá que pugnar por que se garantice una normatividad clara, con contenidos sustantivos, axiológicos y técnicamente elaborada, así como instancias decididas a cumplir y hacerla cumplir, simplificación administrativa, contralorías sociales independientes, observatorios ciudadanos, transparencia, rendición de cuentas, servicio civil de carrera, control del gasto por la finalidad, automatización de trámites.

\section{EL ESTADO CONSTITUCIONAL DE DERECHO}

La noción de Estado de derecho, se contrapone a la idea de Estado anárquico, arbitrario, omnímodo o totalitario. Por Estado de derecho - Rule of law - se entiende básicamente, aquel Estado cuyos diversos órganos e individuos miembros, se encuentran regidos por el derecho

\footnotetext{
${ }^{19}$ LAMO ESPINOZA, Emilio, cit. por Hunneus, Carlos, "Las herencias del régimen autoritario y la corrupción” en: Políticas públicas, probidad o corrupción, Santiago de Chile, Instituto Chileno de Estudios Humanísticos, 2002.

${ }^{20}$ VILlORO TORANZO, Miguel, Derecho Público y Derecho Privado, México, Jus, 1975, p. 18. 
y sometidos al mismo, alude al Estado cuyo poder y actividad están regulados y controlados por el derecho. ${ }^{21}$

No es posible partir de un Estado sin derecho, ni de la identificación del Estado con el derecho, como lo pretendía Hans Kelsen, al afirmar que "El Estado es la personificación del orden jurídico". ${ }^{22}$ Más bien debemos hablar de una continua interacción de ambos conceptos, los cuales viven en una constante "tensión dialéctica" que se resuelve por una síntesis de colaboración y armonía. ${ }^{23}$ "El problema de la relación del derecho y del Estado, se halla íntimamente ligado al problema de la soberanía y el fundamento de la misma. al abordar el problema no conviene perder de vista el carácter dialéctico de esa relación, ni la característica del poder como formador del derecho". ${ }^{4}$

De lo anterior se colige que Estado y derecho, son conceptos y realidades que se implican uno al otro. En nuestros días han llegado a tener un vínculo indestructible a través de la noción Estado de derecho, avance singular de la civilización, que ha ido evolucionando para incorporar a dicha fórmula, la idea de lo social, dando por resuelto lo que los juristas angloamericanos denominan "Welfare state" o "Estado social de derecho", cuya pretensión básica ha sido atemperar las fallas derivadas del individualismo liberal, cuya nota distintiva fue el abstencionismo estatal.

El Estado social de derecho, reúne los elementos de juridicidad, añadiendo como características la tutela a los derechos sociales, la intervención en materia económica, política, social y cultural, así como la búsqueda de la justicia social. A pesar de las variantes introducidas, la concepción del Estado social de derecho conserva, en buena medida, las características y exigencias señaladas anteriormente como propias del Estado de derecho: en particular, la sujeción de los órganos estatales al derecho; pero, simultáneamente, el que las leyes emanen de un órgano popular representativo, bajo procedimientos previstos por otras normas jurídicas; la distribución y control del ejercicio del poder político; la legalidad de la administración y un control judicial suficiente; la garantía de los derechos y libertades fundamentales, etc. Claro está que algunas de esas instituciones jurídico políticas requieren ligeras modificaciones - como ocurre por ejemplo con las limitaciones al desmedido liberalismo económico y con el fortalecimiento del ejecutivo-, a efecto de dar cumplimiento a los objetivos económico sociales del Estado social de derecho. Para poder afirmar que se está en presencia de un Estado social de derecho se requiere que el mismo satisfaga, además de sus objetivos sociales, las exigenciasque se han considerado propias del Estado de derecho. ${ }^{25}$

Paul W. Kahn, profesor de la Facultad de derecho de la Universidad de Yale, sostiene que el Estado de derecho no es una cuestión de verdad revelada ni de orden natural. Es una

\footnotetext{
21 Instituto de Investigaciones Jurídicas de la Universidad Nacional Autónoma de México, Diccionario Jurídico Mexicano, México, Porrúa, Tomo D-H, 1989, p. 328 y ss.

${ }^{22}$ KELSEN, Hans, Teoría pura del derecho, trad.,rrúa-UNAM, 1991, de Roberto José Vernengo, México, Porrúa-UNAM, p. 136.

${ }^{23}$ GONZÁLEZ URIBE, Héctor, Teoría Política, Porrúa, México, 1982, p. 222, 3ra Edición.

${ }^{24}$ Pedroso, Manuel, "Relación entre Derecho y Estado y la Idea de Soberanía”, Revista de la Escuela Nacional de Jurisprudencia, México, U.N.A.M., Tomo XII, Núm. 46, 1950, p. 123.

${ }^{25}$ GONZÁleZ URIBE, Op. Cit., p. 330.
} 
forma de organizar una sociedad bajo un conjunto de creencias que son constitutivas de la identidad de una comunidad y sus miembros individuales. ${ }^{26}$

No obstante las precisiones anteriores, la expresión "Estado de derecho", tiene en el ámbito jurídico una connotación propia e inconfundible que ha evolucionado, abarcando hoy día tanto el mantenimiento de un orden jurídico, como la búsqueda de fines sociales y el desarrollo de la democracia.

Los elementos fundamentales del Estado constitucional de derecho son los siguientes:

1. El reconocimiento de la superioridad y preeminencia de los valores éticos del derecho. La voluntad de asumir soberanamente como propios dichos valores. Un conjunto de reglas que permitan hacer realidad tales valores dentro de una comunidad determinada. Esas reglas deben derivar de la Constitución de cada país y en su conjunto forman el derecho positivo.

2. La primacía de la Constitución y la sujeción de los poderes a ella.

3. Una Constitución como un fenómeno más jurídico que político, de mínimos que establezca principios esenciales, valores fundamentales y el menor número de reglas.

4. Una decreciente densidad legislativa.

5. El reforzamiento del control jurisdiccional de la constitucionalidad.

6. La dimensión normativa-integradora-cultural a que alude Häberle.

7. La fluctuación constitucional está relacionada con cambios formales pero también con procesos interpretativos. En este sentido los intérpretes constitucionales juegan un papel de gran importancia para fijar el contenido de la norma constitucional. ${ }^{27}$

8. La interpretación no es únicamente una forma de interiorizar el texto, sino también de modificarlo. ${ }^{28}$

Los principios fundamentales que deben cumplirse y de los cuales debe partir la formulación de tales reglas en un Estado constitucional de derecho son los siguientes:

1. La existencia de una Constitución escrita, que determina con claridad cuales son los órganos del Estado.

2. La delimitación legal de las correspondientes atribuciones y competencias.

3. La supremacía constitucional sobre cualquier otra norma.

\footnotetext{
${ }^{26}$ KAHN, Paul, El análisis cultural del derecho una reconstrucción de los estudios jurídicos, Traducción de Daniel Bonilla, Barcelona, Biblioteca Yale de Estudios Jurídicos, Gedisa Editorial, 2001, 205 pp.

27 VALADEZ, Diego, Peter Häberle: un jurista para el siglo XXI Estudio Introductorio, México, UNAM, 2001, p.XXXIV.

${ }^{28}$ Idem.

Ciencia JuRÍdicA. Departamento de Derecho. División de Derecho Política y Gobierno, Universidad de Guanajuato - Año 3, No. 5, 2014
} 
4. El poder señala Bobbio, se ejerce "sub lege" y "per lege". "Sub lege" significa que todo poder se encuentra sometido a la ley y "per lege" que el poder se ejerce a través de leyes generales y abstractas. ${ }^{29}$

5. La congruencia y sujeción de todo el orden jurídico a la Constitución, lo que implica que a ella se ajusten todas las leyes, reglamentos, decretos y demás disposiciones de carácter general.

6. El reconocimiento constitucional de los derechos fundamentales.

7. La ponderación en el ejercicio del poder público, la división y colaboración de las tres funciones fundamentales, con un sistema armónico de equilibrios para evitar abusos y extralimitaciones.

8. El establecimiento de mecanismos de participación de la ciudadanía, en los asuntos públicos, mediante una organización electoral confiable, para el logro de un gobierno auténticamente representativo.

9. La pluralidad, veracidad y libre competencia de los medios de información; tales como la radio, Internet, televisión, prensa, etc., que permitan no solo el conocimiento de las actividades gubernamentales, sino su vigilancia y seguimiento.

10. El establecimiento - tanto en la Constitución como en las demás leyes- de un sistema de impugnaciones; esto es, juicios y recursos, tanto jurisdiccionales como administrativos.

Características del Estado constitucional de derecho:

1. Supremacía del orden constitucional, concibiéndolo como expresión de la voluntad general, que debe aplicarse a todos los sujetos sin distinción alguna, siendo de carácter abstracto, sin lugar a especificidades, que dentro de su propia complejidad permite la estabilidad de la estructura del sistema social.

2. La validez de una ley no está dada por su contenido material, sino por su correspondencia y autorización con una ley superior en términos de Kelsen..$^{30}$

\footnotetext{
${ }^{29}$ BOBBIO, N. Norberto, "Fundamento y futuro de la democracia", Conferencia del 29 de abril de 1986, Universidad de Valparaiso, Chile, publicada por Edeval, 1990, punto 7, p. 21 y s.

30 "En razón del carácter dinámico del derecho, una norma solo es válida en la medida en que ha sido creada de la manera determinada por otra norma. Para describir la relación que se establece así entre dos normas, una de las cuales es el fundamento de validez de la otra, puede recurrirse a imágenes espaciales y hablar de norma superior y norma inferior, de subordinación de la segunda a la primera. Un orden jurídico no es un sistema de normas yuxtapuestas y coordinadas. Hay una estructura jerárquica y sus normas se distribuyen en diversos estratos superpuestos. La unidad del orden reside en el hecho de que la creación -y por consecuencia la validez- de una norma está determinada por otra. Op. cit. p. 43.
} 
3. La ley se presume válida en tanto en cuanto haya sido expedida por la autoridad competente, es decir, votada por el cuerpo representativo y publicada de acuerdo con las reglas especiales que contienen la mayor parte de las constituciones. ${ }^{31}$

4. Jerarquía normativa: Cada ley debe ajustarse al procedimiento establecido para su producción, así como a la ley superior que la faculte y la determine.

5. Homogeneidad y coherencia del orden jurídico. Refiere Santiago Nino que: "Debemos presentar una cadena de validez integrada por eslabones [...] si aceptamos que una cierta norma es válida también lo serán las normas que se dicten de acuerdo con ella". ${ }^{2}$

6. La contraposición entre poderes privados y públicos ha dejado de ser clara. Bilbao Ubillos $^{33}$ considera que el poder asume un rostro indiferenciado: Mientras el poder público se privatiza, el privado adquiere connotaciones públicas.

7. "El proceso de democratización, o sea, el proceso de expansión del poder ascendente, se está ampliando de la esfera de las relaciones políticas, de las relaciones en las que el individuo es tomado en consideración en su papel de ciudadano, a la esfera de las relaciones sociales, donde el individuo es tomado en consideración en la diversidad de sus status y papeles específicos". ${ }^{34}$

8. En las relaciones entre las autoridades y los particulares existe un fenómeno de colisión de los intereses de ambos, colisión que se sintetiza o concreta en la creación formal de una ley. ${ }^{35}$

9. La garantía de las libertades y los derechos del ciudadano se aseguran en la medida que está desconcentrado el poder.

10. El poder necesita ser controlado por el mismo y esto se logra separando el poder, separando sus funciones: la legislativa, la ejecutiva y la judicial. La intención, en la práctica, es que estos tres poderes se catalicen unos a otros para evitar cualquier arbitrariedad.

11. No es legítimo privar a cualquiera de los poderes de su competencia constitucional, ya que esto iría en detrimento de las funciones de cada órgano, y en general de la armonía estatal.

\footnotetext{
${ }^{31}$ KELSEN, Hans, Teoría pura del Derecho, traducción de Roberto José Vernengo, México, Porrúa-UNAM, 1991, p. 115

${ }^{32}$ SANTIAGO NINO, Carlos, Introducción al análisis del derecho, 2da. Edición, 12va. Reimpresión, Buenos Aires, Astrea, p. 148.

${ }^{33}$ BILBAO UBILLOS, Juan María, Los derechos fundamentales en la frontera entre lo público y lo privado, Madrid, McGraw Hill, 1997, Nota preliminar, p. XIII.

${ }^{34}$ BOBBIO, Norberto, El futuro de la democracia, México, Fondo de Cultura Económica, 1992, p. 42.

${ }^{35}$ Cfr. LAMO DE ESPINOSA, Emilio, Los delitos sin víctima. Orden social y ambivalencia moral, segunda edición, Madrid, Alianza Editorial, 1993, pp. 95.
} 
12. La autonomía y límite funcional de los poderes, se encuentra en la noción misma de la separación, teniendo en cuenta que nunca podrán sobrepasar lo que la ley haya autorizado a cada uno.

El Estado constitucional de derecho o modelo garantista, es un sistema que tiene por finalidad la protección de los derechos fundamentales de los individuos. Ferrajoli reconoce tres modelos de garantismo, ${ }^{36}$ que, desde este punto de vista, "el 'ser' o la 'existencia' del derecho no es ya derivado ni de la moral ni se halla en la naturaleza, sino que es 'establecido' o 'elaborado' por hombres, como ellos lo quieren y [...] lo piensan”. Refiere dos significados genéricos: un modelo de derecho y una propuesta de teoría general del derecho. ${ }^{37} \mathrm{El}$ primer supuesto se presenta como una alternativa al Estado de derecho; el segundo, como una superación de los reduccionismos iusnaturalistas y positivistas. Ambos significados confluyen en un axioma distintivo: el derecho como garantía de limitación al poder.

El Estado constitucional de derecho asume y garantiza todos y cada uno de los elementos, principios y características referidos, como la conquista más importante del derecho contemporáneo no solo por lo que hace a las formas de producción, sino en cuanto a los contenidos producidos.

La razonabilidad, debe ser un derecho humano esencial, mínimo y accesible que significa ir más allá de la mera legalidad, coadyuvando a eliminar la arbitrariedad.

En todo Estado constitucional de derecho la Constitución debe prever explícitamente la obligación de emitir decisiones razonables. El reconocimiento constitucional expreso de este derecho fundamental, obligará a que las autoridades trabajen en lograr la congruencia, exhaustividad, profundidad y coherencia lógica de toda decisión.

\section{EL DERECHO A LA RAZONABILIDAD COMO DERECHO FUNDAMENTAL}

El aserto "ningún derecho fundamental es absoluto", es admitido por la mayoría de la doctrina, por lo que de su ejercicio es frecuente que surjan valores o derechos constitucionales en conflicto. El derecho a la razonabilidad tiene un doble ámbito de significación: individual e institucional. La dimensión subjetiva por ser un derecho fundamental y la dimensión objetiva, por la cual debido a su significación constitucional debe hacerse incluir como parte del contenido constitucional esencial, como obligación del poder público de realizar actuaciones tendentes a favorecer su plena vigencia. Como derecho fundamental impone una obligación concreta a toda autoridad de respetarlo. Si bien está vinculado con otros derechos, es perfectamente diferenciable. No se trata de un derecho irrestricto, en tanto está sujeto a los límites genéricos, específicos e implícitos que tiene todo derecho fundamental. Por tanto, debe ser oponible como derecho positivo — no natural — ante los juzgadores.

En el proceso de constitucionalización de los derechos fundamentales, el derecho a la razonabilidad debe tener un lugar específico. Siendo parte de la estructura fundamental del ordenamiento, el derecho a la razonabilidad implica el derecho a la argumentación como

\footnotetext{
${ }^{36}$ FERRAJOLI, Luigi, Derecho y razón, Madrid, Trotta, 2001, p. 85.

37 FERRAJOLI, Luigi, Los fundamentos de los derechos fundamentales, Madrid, Trotta, 2005, p. 290; véase también Ferrajoli, Luigi, Garantismo. Una discusión sobre derecho y democracia, Madrid, Trotta, 2006, p. 47.
} 
parte de la seguridad jurídica, por ser inherente a la dignidad de la persona humana, con un carácter universal, inalienable, imprescriptible, intransferible e inviolable.

La constitucionalización de los derechos históricamente ha significado la limitación del poder, basada en una determinada filosofía que hunde sus raíces en la Ilustración. Esa filosofía no se limita a constituir una propuesta de Filosofía política, ya que, además, tiene directas manifestaciones en el marco del ordenamiento jurídico. Las limitaciones a las que el constitucionalismo pretende someter al poder son de naturaleza jurídica. En este sentido, la Constitución, se presenta como una pieza insustituible del entramado constitucionalista y de su vocación limitativa del poder. ${ }^{38}$

No se trata de uno de esos derechos reconocidos a ciertos estados excepcionales en la existencia humana o de derechos atribuibles solo a categorías o grupos de ciudadanos por razones vinculadas a su situación social o cultural discriminada-mujeres, emigrantes, etc.-, por la especial debilidad, derivada de razones de edad -niños-, o de razones físicas o psíquicas temporales o permanentes - minusválidos-, o del puesto de inferioridad que ocupan en una determinada relación social -consumidores, usuarios o administrados-. ${ }^{39}$

En el plano de la dogmática de los derechos fundamentales, la dimensión institucional ${ }^{40}$ del derecho a la razonabilidad tiene un papel relevante en la interpretación de los demás derechos fundamentales. Al resolver los casos en que se encuentren comprendidos derechos fundamentales, el intérprete no podrá limitarse a establecer cuál es el ámbito de actuación protegido al individuo por el derecho de que se trate, cuál es el contenido en su dimensión subjetiva, y con aclarar si ese ámbito ha sido excedido o violado. En todo caso, se impone el deber de interpretación del ordenamiento jurídico de conformidad con la Constitución, en mérito de la seguridad jurídica inmanente al Estado de derecho, en que la argumentación con toda nitidez conduzca a la decisión, lo cual no es otra cosa que la razonabilidad.

Esa dimensión institucional posibilita el logro de los fines sociales proclamados por la Constitución, la cual no puede ni debe subordinarse ni contraponerse aisladamente a la dimensión como derecho individual; tampoco puede llevarse a cabo a una relación medio-fin. Más bien está, con respecto a la dimensión jurídico-individual, en una relación recíproca y de paridad jerárquica, tal y como Kauffman la supuso y Hauriou la definió. ${ }^{41}$

Es obsoleta la teoría tradicional de los derechos fundamentales como derechos frente al Estado o como simples límites del poder estatal, en función a que el poder público, debe realizar una política de los derechos fundamentales, tomando una posición activa en la pro-

\footnotetext{
${ }^{38}$ ANSUÁTEGUI ROIG, Francisco Javier, Los desafíos de los derechos humanos hoy , Primera Sesión. Los derechos humanos en la historia y su actualización, España, Universidad Carlos III de Madrid, 2008, p. 83.

39 SQUELLA NARDUCCI, Agustín, Introducción al Derecho > Los Derechos Fundamentales de la persona humana, Universidad de Valparaíso, Chile, 2011, p. 257, versión en línea: http://doctrina.vlex.cl/vid/denominacion-concepto-historia-humanos-324896839. 23 de febrero de 2013.

${ }^{40}$ Para Parejo, Alfonso "la idea motriz de la doctrina de las garantías institucionales es la de 'hacer resistentes' una serie de regulaciones que, por deficiencias de la norma fundamental de la época weimariana y la ausencia en ésta de técnicas de protección de su orden básico, corrían el riesgo de verse desvirtuadas en cuanto entregadas -a través de la reserva de Ley- a la disponibilidad del legislador ordinario. Pero esta situación es propia y específica de una Constitución histórica, no siendo generalizable ni absolutizable, con lo que los fundamentos mismos de la doctrina aparecen como contingentes. La sola variación de los presupuestos constitucionales de que parte implicaría, pues, en principio, su obsolescencia", Parejo Alfonso, Luciano, Garantía institucional y autonomías locales, Madrid, Instituto de Estudios de Administración Local, 1981, pp. 23, 26, y ss.

${ }^{41}$ HÄBERLE, Peter, La garantía del contenido esencial de los derechos fundamentales: En la Ley Fundamental de Bonn, traducción de Francisco Fernández Segado, Madrid, Dykinson, 2003, pp. 75-78.
} 
moción de los derechos y favorecimiento las condiciones que hagan posible su ejercicio efectivo y pleno.

\section{CONCLUSIONES}

La constitucionalización de los derechos adquiere sentido en el marco del nuevo paradigma jurídico y político de protección de los derechos humanos. Prever la razonabilidad como un derecho fundamental, no ya como un principio subsumido, subrepticio o implícito dentro del debido proceso, es un imperativo, por lo que debemos pugnar por su incorporación expresa en la Constitución Política de los Estados Unidos Mexicanos.

El derecho a la razonabilidad, debe ser establecido como un derecho humano esencial, mínimo y accesible que significa ir más allá de la mera legalidad, coadyuvando a eliminar la arbitrariedad.

El derecho a la razonabilidad debe, por tanto, protegerse mediante reglas, procedimientos y organización adecuados. El derecho a la razonabilidad debe tener un lugar específico en el ámbito de los derechos humanos.

El derecho a la razonabilidad no debe ser solo un límite para la administración, sino un imperativo para el poder público. Constitucionalmente, el derecho a la razonabilidad debe estar inscrito dentro de los derechos fundamentales. Entendiéndose como la garantía de que toda autoridad emita decisiones jurídicas razonables, no solo fundadas, motivadas y de acuerdo al debido proceso.

VII. FUENTES

AGUILERA PORTALES, Rafael Enrique, et al, Neoconstitucionalismo, democracia y derechos fundamentales, México, Porrúa, 2010.

ÁLVAREZ GARDIOL, Ariel, Introducción a una teoría general del derecho: El método jurídico, Buenos Aires, Astrea, 1975.

ANSUÁTEGUI ROIG, Francisco Javier, Los desafíos de los derechos humanos hoy > Primera Sesión. Los derechos humanos en la historia y su actualización, España, Universidad Carlos III de Madrid, 2008.

BAZÁN, José Luis y MADRID, Raúl, "Racionalidad y Razonabilidad en el Derecho”, Chile, Revista Chilena de Derecho, Pontificia Universidad Católica de Chile, Vol. 18, No 2, 1991.

BIDART CAMPOS, Germán, Manual de la Constitución Reformada, Buenos Aires, Ediar, 1999, Tomo I.

BILBAO UBILLOS, Juan María, Los derechos fundamentales en la frontera entre lo público y lo privado, Madrid, McGraw Hill, 1997.

BOBBIO, Norberto, El futuro de la democracia, México, Fondo de Cultura Económica, 1992. , "Fundamento y futuro de la democracia", Conferencia del 29 de abril de 1986, Valparaíso, Universidad de Valparaíso, publicada por Edeval, 1990. 
CIANCIARDO, Juan, “El punto final para el principio de razonabilidad.” Periódico La Nación, versión en línea: http://www.lanacion.com.ar/371576-el-punto-final-para-elprincipio-de-razonabilidad.

DEANE, Matías Mariano, El Principio de Razonabilidad, Argentina, Colegio de Magistrados y Funcionarios de la Provincia de Buenos Aires, s.a.

FERNÁNDEZ DE LA MORA, Gonzalo, “El Imperativo de Razonabilidad”, Madrid, revista Razón Española, Madrid, Marzo-Abril 2000, 2000.

FERRAJOLI, Luigi, Derecho y razón, Madrid, Trotta, 2001. , Los fundamentos de los derechos fundamentales, Madrid, Trotta, 2005. , Garantismo. Una discusión sobre derecho y democracia, Madrid, Trotta, 2006.

GONZÁLEZ URIBE, Héctor, Teoría Política, México, Porrúa, 1982, 3ra. Edición.

HÄBERLE, Peter, La garantía del contenido esencial de los derechos fundamentales : En la Ley Fundamental de Bonn, traducción de Francisco Fernández Segado, Madrid, Dykinson, 2003.

HARO, Ricardo, “La Razonabilidad ylas Funciones deControl,” Ius etPraxis, 2001, versiónOnline : http://www.scielo.cl/scielo.php?pid=S0718-00122001000200008\&script=sci_ arttext.

IHERING, Rudolf von, La lucha por el Derecho, Buenos Aires, Valletta Ediciones, 2004, 2da. Edición.

Instituto de Investigaciones Jurídicas de la Universidad Nacional Autónoma de México, México, Diccionario Jurídico Mexicano, Porrúa, Tomo D-H, 1989.

JIMÉNEZ CAMPO, Javier, “El legislador de los derechos fundamentales", Estudios de Derecho Público en Homenaje a Ignacio de Otto, España, Universidad de Oviedo, 1993.

KAHN, Paul, El análisis cultural del derecho una reconstrucción de los estudios jurídicos, Traducción de Daniel Bonilla, Biblioteca Yale de Estudios Jurídicos, Barcelona, Gedisa Editorial, 2001.

KELSEN, Hans, Teoría pura del derecho, Traducción de Roberto José Vernengo, México, Porrúa-UNAM, 1991.

LAMO DE ESPINOSA, Emilio, Los delitos sin víctima. Orden social y ambivalencia moral, segunda edición, Madrid, Alianza Editorial, 1993.

PAREJO ALFONSO, Luciano, Garantía institucional y autonomías locales, Madrid, Instituto de Estudios de Administración Local, 1981.

PEDROSO, MANUEL, "Relación entre Derecho y Estado y la Idea de Soberanía”, Revista de la Escuela Nacional de Jurisprudencia, México, U.N.A.M., Tomo XII, Núm. 46, 1950.

POPPER, Karl, Conjeturas y refutaciones, Barcelona, Paidós, 1994. , La sociedad abierta y sus enemigos, Barcelona, Paidós, 2000. 
RAWLS, John, Liberalismo político, traducido por Sergio René Madero Báez, México, FCE, UNAM, 1995.

SANTIAGO NINO, Carlos, Introducción al análisis del derecho, Buenos Aires, Astrea, 1973, 2da. Edición, 12va. Reimpresión.

SCHULZ, Fritz, Derecho romano clásico, Traducción de José Santa Cruz Teigeiro, Barcelona, Bosch, 1960.

SQUELLA NARDUCCI, Agustín, Introducción al Derecho > Los Derechos Fundamentales de la persona humana, Chile, Universidad de Valparaíso, 2011, versión en línea: http://doctrina.vlex.cl/vid/denominacion-concepto-historia-humanos-324896839.

VALADEZ, Diego, Peter Häberle: un jurista para el siglo XXI Estudio Introductorio, México, UNAM, 2001.

VARGAS ALFARO, Marvin de Jesús, El control de Razonabilidad de las Leyes en la Jurisprudencia de la Sala Constitucional de la Corte Suprema de Justicia, Tesis para optar por el Grado de Licenciado en Derecho, San José, Costa Rica, Universidad de Costa Rica, 2009.

VILlORO TORANZO, Miguel, Derecho Público y Derecho Privado, México, Jus, 1975. 
